\title{
REVIEW
}

\section{NEUROTRANSMITTER ORGANIZATION AND CONNECTIONS OF TURTLE CORTEX: IMPLICATIONS FOR THE EVOLUTION OF MAMMALIAN ISOCORTEX}

\author{
Anton ReINER \\ Department of Anatomy and Neurobiology, The University of Tennessee-Memphis, \\ Memphis, TN 38163, U.S.A. (Tel. 901-577-8298; Fax 901-528-7193)
}

(Received 7 October 1992; accepted 11 November 1992)

\begin{abstract}
Telencephalic cortex in turtles is a simple three layered-structure. The dorsal most part of this structure is thought to resemble the reptilian forerunner of at least parts of mammalian isocortex. This dorsal part of turtle cortex contains several functionally distinct regions that show similarity in their connections and function to specific areas in mammalian isocortex. The types of neurons found in turtle dorsal cortex (as defined by their morphology and neurotransmitter content) also show great similarity to those observed in mammals, with the major exception that turtle cortex appears to lack the types of neurons found in granular and supragranular layers of mammalian isocortex. Similar results have also been observed in other living reptiles. Thus, one major step in the evolution of reptilian cortex into mammalian cortex must have been the addition of the types of neurons found in the granular and supragranular layers of mammalian isocortex. These observations for turtles also suggest that turtle cortex in particular and reptilian telencephalic cortex in general must differ functionally from mammalian isocortex with respect to those features associated with the laminar and columnar organization of isocortex. These issues are discussed in more detail below and in Reiner (1991).
\end{abstract}

\section{INTRODUCTION}

\section{Description of turtle telencephalon}

Basic anatomy. The telencephalon in turtles (Fig. 1) at first glance shows gross dissimilarity to that in mammals. Three major cell groups of the turtle telencephalon are of interest for the present discussion, the basal ganglia, the dorsal ventricular ridge (DVR) and the cortex. Only with the advent of recent neuroanatomical and histochemical methods have the identities and relationships of these telencephalic regions become clear. The basal ganglia occupies the basolateral part of the telencephalic hemisphere in turtles and it is readily identifiable by a variety of histochemical criteria (Reiner et al., 1984a; Reiner and Anderson, 1990). Based on such criteria and connectional (hodological) considerations, it is clearly homologous to the structure of the same name in mammalian species (Reiner et al., 1984a). Also present in the basolateral telencephalon in turtles, but not discussed further here, are homologues of the substantia innominata region, the ventral pallidal region and the ventral striatum. Around the inferior horn of the lateral ventricle, the basal ganglia is continuous with the septum. The DVR, which is the large region of the lateral telencephalic wall that overlies the basal ganglia in turtles (and in other reptiles and in birds) and bulges into the lateral ventricle, was the subject of much misidentification earlier this century. Owing to its appearance as a nonlaminated structure lying beneath the pallial mantle of the telencephalon, the DVR was regarded as a portion of the basal ganglia that was uniquely hypertrophied in birds and reptiles (Ariëns-Kappers et al., 1936; Reiner et al., 1984a). With more precise modern neuroanatomical methods, however, it has become very clear that the DVR is not part of the basal ganglia. In fact, the DVR shows many of the hodological, functional and developmental features that characterize the isocortex of mammals (Karten, 1969; Reiner et al., 1984a; Karten and Shimizu, 1990). The DVR, however, does not show two defining features of mammalian isocortex: lamination and a topographic location at the outer surface of the telencephalon.

Finally, the outer upper surface of the turtle telencephalon is occupied by a three-laycred structurc termed the cortex (Fig. 1). The cortex actually consists of three separate cortical fields, a medial (with medial plus dorsomedial subdivisions), a dorsal, and a lateral. As can be seen, the dorsomedial and medial cortices lie medial to the lateral ventricle and form the medial telencephalic wall. The dorsal cortex occupies the dorsal most portion of the telencephalon, overlies the lateral ventricle and is continuous medially with the histologically similar dorsomedial and medial cortices (Johnston, 1915; Reiner, 1991). The lateral (or olfactory or pyriform 

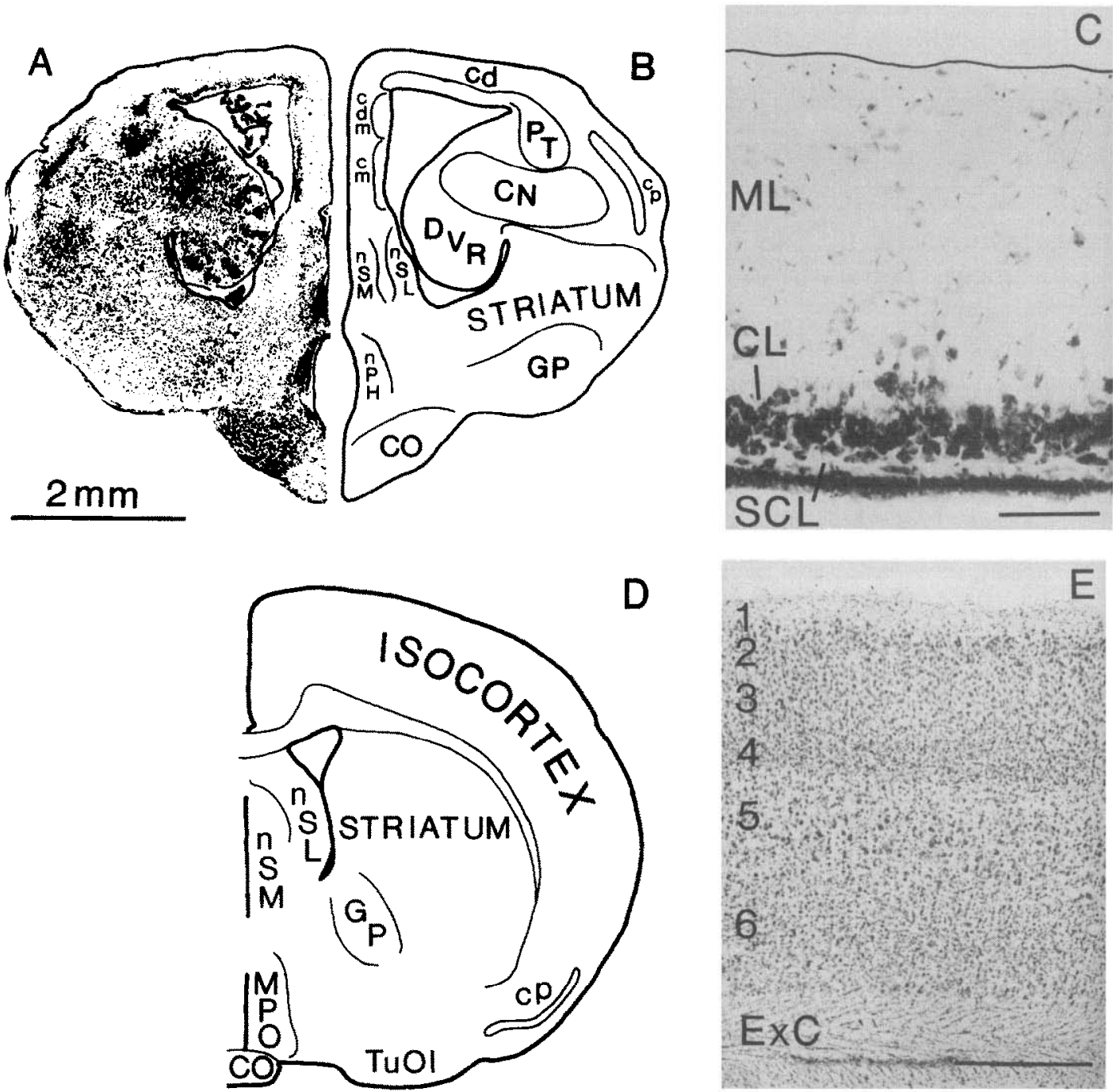

Fig. 1. Photomicrographs and schematics illustrating and comparing the organization of turtle and mammalian telenecphala. (A) High contrast photomicrograph of a cresyl violet stained transverse section through the telencephalon of a painted turtle at the level of the anterior commissure juxtaposed to a line drawing (B) of this same section. The major telencephalic subdivisions are identified. The dorsal cortex constitutes a thin piece of tissue overlying the lateral ventricle and grades into the pallial thickening laterally. (C) High power photomicrograph of turtle dorsal cortex showing its cytoarchitectonic and laminar organization. $A$ line has been drawn along the pial surface to accentuate its location. The scale bar equals $100 \mu \mathrm{m}$. (D) Line drawing of a transverse section of rat telencephalon through the level of the anterior commissure, presented for comparison to the turtle telencephalic section shown in A and B. (E) High power photomicrograph of rat cortex, with the individual layers indicated. Note the much greater laminar and cytoarchitectonic complexity, compared to the turtle cortex shown in $\mathrm{C}$. The scale bar equals $500 \mu \mathrm{m}$. Abbreviations: CL, cellular layer of cortex; CN, core nucleus of the DVR; CO, optic chiasm; $\mathrm{cd}$, dorsal cortex; cdm, dorsomedial cortex; $\mathrm{cm}$, medial cortex; $\mathrm{cp}$, pyriform cortex; DVR, dorsal ventricular ridge; ExC, external capsule; GP, globus pallidus; $M L$, molecular layer of cortex; MPO, medial preoptic area; $\mathrm{nPH}$, periventricular hypothalamic nucleus; $\mathrm{nSL}$, lateral septal nucleus; $\mathrm{nSM}$, medial septal nucleus; PT, pallial thickening; SCL, subceilular layer of cortex; TuOl, olfactory tubercle.

cortex) is situated lateral to the dorsal cortex and occupies a prominent dorsolateral bulge in the telencephalic wall. The lateral cortex is different in that it does not overlie any part of the lateral ventricle and is not continuous with dorsal cortex, at least not at levels anterior to the anterior commissure. An important cell group termed the pallial thickening extends from the lateral edge of the dorsal pallium and curves around the lateral ventricle to about the dorsal most part of the DVR. The part of the DVR abutted by the pallial thickening is called the core nucleus. The pallial thickening, which is considered a lateral subpallial extension of the dorsal cortex, separates the dorsal and lateral cortices. Lateral, dorsal, dorsomedial and medial cortices are typically present in all reptiles and have generally similar locations.

General comparison to mammals. In contrast, the mammalian telencephalon seems to consist of fewer 
basic parts (Fig. 1). Centrally and basally, the telencephalon in mammals consists of the basal ganglia, ventral striatal/pallidal complex and substantia innominata. Surrounding the basal ganglia and separated from it by the fibers of the external capsule is the isocortex. The isocortex of mammals is, histologically and cytoarchitectonically, a neural structure that is unique to mammals. Although the complexity of individual cortical layers varies from one cortical area to another and from one mammalian species to another, all mammals possess an isocortex that is six-layered. A six-layered isocortex, however, has not been observed in the cerebral hemispheres in any nonmammalian species (Ariëns-Kappers et al., 1936). Figure 1 shows clearly that such a cortical architecture is not evident in the telencephalic cortex of turtles. Since the isocortex has been thought to provide the neural substrate for the behavioral adaptiveness of mammals, considerable interest has focused on the evolutionary origins of isocortex (Johnston, 1915; Ariëns-Kappers et al., 1936; Karten, 1969; Northcutt, 1981; Ulinski, 1990). Since early in this century, it has been widely accepted that the dorsal cortex in modern reptiles may resemble the forerunner of mammalian isocortex that was present in the stem reptiles. Thus, information on the structure and function of the dorsal cortex in such a presumably primitive modern reptilian group as turtles has been considered of importance for understanding the evolutionary history of mammalian isocortex. The following sections will briefly describe what is known of the anatomical and functional organization of the dorsal cortex in turtles, relate this to what is known of the neurochemistry of dorsal cortex neurons and their inputs, and put these data into the context of the evolution of mammalian isocortex.

\section{Anatomy and physiology of turtle telencephalic cortex}

Connectivity. A considerable amount of data from modern neuroanatomical and embryological studies on turtles supports the notion that dorsal cortex contains specific regions that are comparable to specific regions of mammalian isocortex (Källen, 1951; Orrego, 1961; Ebner, 1976). This evidence is most complete for a region of dorsal cortex, termed visual dorsal cortex, that has many similarities to mammalian striate cortex (Fig. 2). For example, this portion of dorsal cortex has many of the same inputs as striate cortex: (1) glutamatergic thalamic input from a cell group that corresponds to the dorsal lateral geniculate nucleus of mammals (Ebner, 1976; Ulinski, 1988; Larson-Prior et al., 1991); (2) basal telencephalic input from cholinergic neurons corresponding to the nucleus basalis of mammals (Mufson et al., 1984; Ouimet et al., 1985); (3) noradrenergic input from locus coeruleus (Parent and Poitras, 1974; Ouimet et al., 1985); (4) serotonergic input from the raphe cell groups of the hindbrain (Parent, 1973; Ouimet et al., 1985); and (5) peptidergic input from the lateral hypothalamic-supramammillary region (Reiner et al., 1985). In addition, turtle visual dorsal cortex has two of the major efferent projections characteristic of striate cortex, a projection back to the dorsal lateral geniculate nucleus and a projection to the tectum (Hall et al., 1977; Ulinski, 1986). Ulinski $(1986,1988)$ has recently pointed out that the portion of the turtle telencephalon resembling mammalian striate cortex also includes the pallial thickening. Although fewer data are available for

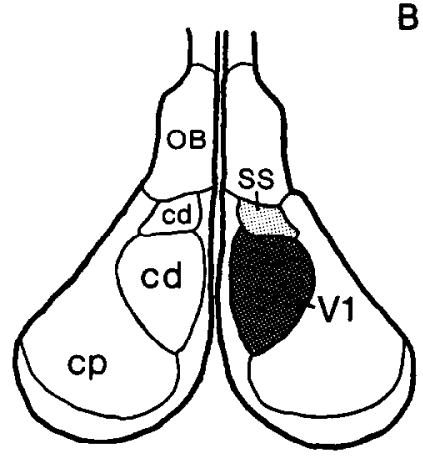

Fig. 2. Line drawing schematics illustrating the location and extent of the major thalamorecipient sensory areas in the turtle cortex and DVR. (A) Line drawing of a transverse section at the level of the anterior commissure (midline is to the left). The dorsal cortex plus pallial thickening is marked as V1, the primary visual area receiving visual input from the retinorecipient dorsal lateral geniculate nucleus. The core nucleus within the DVR is noted as V2, the secondary visual area receiving visual input from the tectorecipient nucleus rotundus of the thalamus. The ventromedial part of the DVR is noted as A, the primary auditory area receiving auditory input from the nucleus reuniens of the thalamus, which itself receives input from the inferior colliculus. (B) View of the dorsal surface of the cerebral hemispheres of turtle, showing the location and extent of the somatosensory (SS) and primary visual (V1) portions of the dorsal cortex. Abbreviations: cd, dorsal cortex; cp, pyriform (olfactory) cortex; CP, optic chiasm; GP, globus pallidus; $\mathrm{OB}$, olfactory bulb. 
other reptiles, several studies indicate the presence in lizards of at least the subpallial (i.e., pallial thickening) portion of visual dorsal cortex (see Reiner, 1991). These overall similarities among different species of reptiles and mammals suggest strongly that visual dorsal cortex of reptiles and striate cortex of mam* mals had their common origin in a visual dorsal cortex-like structure in the reptiles ancestral to living reptiles and mammals. Turtles also possess a somatosensory region in rostral dorsal cortex that might be comparable to mammalian somatosensory/somatomotor cortex (Fig. 2) (Orrego, 1961; Hall et al., 1977).

Cytoarchitecture. In cryptodire turtles, the dorsal cortex is histologically much simpler in its cytoarchitecture than the mammalian isocortex and consists of three layers (Fig. 1): (1) a broad superficial molecular layer that contains a few scattered neurons, (2) a thin perikarya-rich cellular layer, and (3) a thin subcellular layer that contains a few neurons (Smith et al., 1980). This histological organization appears to be the primitive pattern for dorsal cortex in reptiles since it is observed in all cryptodire turtles, in lizards and in snakes (Johnston, 1915; Durward, 1930; Ebbesson and Voneida, 1969; Ulinski, 1974; Davila et al., 1986; Guirado et al., 1987). The medial and dorsomedial cortices also show such a trilaminar arrangement in all reptiles. Thus, based on the observed similarities among living reptiles, it appears highly likely that the reptiles ancestral to living reptiles possessed a dorsal cortex that was histologically similar to that in cryptodire turtles. Since the dorsal cortex in all reptiles has a lateral subcortical extension called the pallial thickening, it is very likely that a pallial thickening was also present as part of dorsal cortex in ancestral reptiles.

Cellular anatomy and neurochemistry of turtle telencephalic cortex

Anatomy and physiology of cortical neurons and the neurochemistry of their inputs. Two basic types of neurons are found in turtle dorsal cortex, pyramidal and nonpyramidal (Smith et al., 1980; Connors and Kriegstein, 1986). The pyramidal neurons, which are located in the cellular layer, possess dendrites that branch widely and extend out toward the pial surface. The nonpyramidal neurons are located in all cortical layers and are very diverse in their morphologies. In general, however, the nonpyramidal neurons tend to have dendrites that branch more radially or horizontally than those of pyramidal neurons (Fig. 3). The pyramidal neurons appear to be the main input and output neurons of turtle cortex, while the nonpyramidal neurons appear to be involved in local circuit interactions (Smith et al., 1980; Connors and Kriegstein, 1986). Anatomical studies have shown that thalamic inputs terminate on the dendrites of cortical neurons in the outer part of the molecular layer (Fig. 3) (Smith et al., 1980). Electrophysiological studies have shown that activation of this
SIMPLIFIED WIRING DIAGRAM OF TURTLE CORTEX

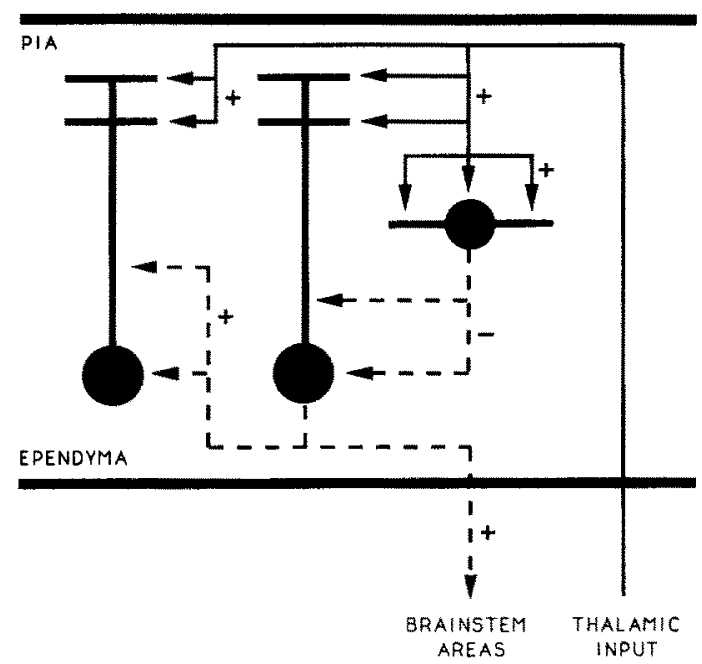

Fig. 3. A simplified wiring diagram of turtle dorsal cortex. The schematic shows that: (1) thalamic input to cortex has excitatory input to pyramidal neurons (the two neurons on the left) and nonpyramidal neurons (the neuron on the right); (2) nonpyramidal neurons have inhibitory input to pyramidal neurons; (3) pyramidal neurons have excitatory input to each other (and to nonpyramidal neurons, which is not shown); and (4) pyramidal neurons have excitatory descending projections.

thalamic input leads to excitation of both pyramidal and nonpyramidal neurons in the cellular layer (Kriegstein and Connors, 1986; Larson-Prior et al., 1991). This excitation is blocked by non-NMDA type glutamate receptor antagonists, thus suggesting that the thalamocortical input is glutamatergic and excitatory (Kriegstein and Connors, 1986; Larson-Prior et al., 1991). In support of this conclusion is the anatomical observation that neurons in the thalamic sensory cell groups projecting to the cortex are glutamatergic and the cortex of turtles is rich in glutamate receptors (Young et al., 1990; A. Reiner, R. L. Albin and E. C. Richfield, unpub. obs.). In addition to the excitation observed in pyramidal neurons upon stimulation of thalamocortical afferents, these neurons also exhibit prominent IPSPs (Kriegstein and Connors, 1986; Larson-Prior et al., 1991). Since GABA antagonists block this inhibitory response of pyramidal neurons (Kriegstein and Connors, 1986; Larson-Prior et al., 1991), these results indicate that the inhibition is generated by GABAergic neurons (apparently intrinsic to the cortex) that had been stimulated by the activation of the thalamic input (either directly or indirectly via the pyramidal neurons) (Fig. 3). In support of the latter conclusion, GABAergic nonpyramidal neurons are abundant in turtle cortex and make synaptic contact with pyramidal neurons (Smith et al, 1980; Blanton et al., 1987; Reiner, 1991) and GABAA receptors are extremely abundant in turtle cortex (Schegel $e t$ al., 1986; A. Reiner, R. L. Albin and E. C. Richfield, unpub. obs.). Finally, pyramidal neurons in turtles 
also have local circuit excitatory connections, which appear to use both NMDA and non-NMDA-type glutamate receptors and nonglutamatergic receptors (Larson-Prior et al., 1991). In these various respects (the neuronal types present in cortex, their somatodendritic morphology, their electrophysiological characteristics, their connectivity with each other and with their thalamic input, and the neurotransmitter mechanisms involved), the fundamental features of the organization of turtle cortex are similar to those of mammalian cortex (Smith et al., 1980; Connors and Kriegstein, 1986; Kriegstein and Connors, 1986; Larson-Prior et al., 1991). Thus, the basic neuronal building blocks of the cortex and their functional properties are similar in turtles and mammals. As will be seen below, in both turtles and mammals, nonpyramidal neurons are diverse in the types of neurotransmitters they contain, while pyramidal neurons appear to use glutamate as a neurotransmitter. Despite the similarities, however, there are some major differences between turtle and mammalian cortex, as also discussed below.

Although the thalamocortical input to cortex utilizes glutamate in turtles, some thalamocortical neurons (and seemingly the majority of geniculocortical neurons) and their cortical terminals also contain the neuropeptides neurotensin and LANT6 (Reiner, 1992). The functional significance of this for cortical neurotransmission has not been clarified. Neurons in the cellular layer of cortex also receive an input that co-contains the neuropeptides SP (substance P), VIP (vasoactive intestinal polypeptide), CCK8 (the C-terminal octapeptide of cholecystokinin) from neurons of the supramammillary-lateral hypothalamic region (Reiner et al,, 1985; Reiner, 1991). The influence of this input on cortical neurons is also unknown, as is the influence of the noradrenergic input from locus coeruleus (which is concentrated near the pial surface). The serotonergic input from the raphe (which is distributed throughout the depth of turtle dorsal cortex), however, is known to inhibit the spontaneous activity of cortical neurons in turtles (Shen and Kriegstein, 1986). Finally, the cholinergic input from the basal forebrain, which ends in the molecular layer, has been found to act on cortical neurons through muscarinic mechanisms (utilizing the M1 class of receptors) in turtles (Schlegel et al., 1986; Blanton et al., 1986). Electrophysiological studies indicate that the response of cortical pyramidal neurons to muscarinic agonists is biphasic, consisting of early inhibition followed by slow excitation (Blanton et al., 1986). In terms of the known effects of the various specific cortical afferent systems on the excitability of individual cortical neurons, the patterns of response appear to be very similar in turtles and mammals.

Columnar arganization. A hallmark of mammalian isocortex that appears to be absent from cortex in turtles (and reptiles in general) is columnar organization (Rakic, 1988; Reiner, 1991). Columnar organization appears to derive from two morphological properties of mammalian isocortex: (1) the narrow and radial disposition of the dendritic trees of most cortical neurons, and (2) the presence of neurons in cortical layers $2-4$ whose axons terminate on other neurons in the same cortical column (Szentagothai, 1978,1983; Jones, 1981; Eccles, 1984; Lund, 1984). Although most pyramidal cortical neurons in turtles have radially oriented dendritic trees (as in mammals), the absolute width of the trees of individual neurons is greater than in mammalian isocortex (Ebner, 1976; Smith et al., 1980). Perhaps more significantly, an individual vertical slab of chelonian cortex is relatively cell poor and appears to lack the types of neurons found in cortical layers 2-4 in mammals, as defined by the transmitter content of those neurons and as defined by the connections of those neurons. Thus, turtle cortex (and reptilian cortex in general) does not show columnar organization. Data further supporting this conclusion are discussed in the following sections.

Neurochemistry of cortical neurons. Several different neurotransmitters or neuropeptides are found in cortical neurons in turtles, including both pyramidal and nonpyramidal neurons. In general, most of the same neurotransmitters and neuropeptides found in mammalian isocortex are found in turtle cortex, with the major exception that transmitter-specific cell types found predominantly in layers $2-4$ in mammalian isocortex are absent from turtle cortex (Table 1). For example, three different neurotransmitter-specific groups of nonpyramidal neurons that are bipolar in morphology, have small (approximately $10 \mu \mathrm{m}$ in diameter) fusiform cell bodies and are primarily located in layers 2 and 3 have been described in mammals (see Reiner, 1991). One group of these contains vasoactive intestinal polypeptide (VIP), a second contains the C-terminal octapeptide of cholecystokinin (CCK8) and the third contains acetylcholine. In turtles, no unequivocally VIP + or CHAT + neurons and extremely few CCK8 + neurons are present in cortex and PT (Figs 3, 4). The paucity of CCK8 + perikarya in cortex in turtles is consistent with the biochemical demonstration that CCK8 levels are low in cortex of turtles (Reiner and Beinfeld, 1985).

In contrast, transmitter-specific types of neurons found specifically in layers 5-6 of mammalian cortex (for example, the neuropeptides substance $P$ and the neurotensin-related hexapeptide LANT6) or throughout layers 2-6 (for example, somatostatin, neuropeptide Y, GABA, enkephalin and glutamate) are found in turtle dorsal cortex. Substance P-containing (SP+) cortical neurons in mammals appear to typically be multipolar nonpyramidal neurons primarily localized to the infragranular cortical layers (Jones et al., 1988; Reiner, 1991). This is also true of the LANT6 + neurons of mammalian cortex. In turtles, both SP + and LANT6 + nonpyramidal neurons (both typically with a multipolar morphology) 
Table 1. Comparison of the types of neurons found in mammalian cortex to those found in turtle and lizard cortex

\begin{tabular}{lcccc}
\hline Phenotype & Morphology & $\begin{array}{c}\text { Location in } \\
\text { mammals }\end{array}$ & $\begin{array}{c}\text { Present in } \\
\text { turtles }\end{array}$ & $\begin{array}{c}\text { Present in } \\
\text { lizards }\end{array}$ \\
\hline VIP+ & radial & $2 / 3$ & no & unkown \\
CCK8+ & radial & $2 / 3$ & no & no \\
Cholinergic & radial & $2 / 3$ & no & no \\
Cholinergic & nonpyramidal & absent & no & yes \\
Substance P & nonpyramidal & $5 / 6$ & yes & unknown \\
LANT6 & nonpyramidal & $5 / 6$ & yes & yes \\
Somatostatin & nonpyramidal & $2-6$ & yes & yes \\
Neuropeptide Y & nonpyramidal & $2-6$ & yes & yes \\
GABA & nonpyramidal & $2-6$ & yes & yes \\
Glutamate & pyramidal & $2-6$ & yes & unknown \\
Enkephalin & nonpyramidal & $2-6$ & yes & unknown \\
Parvalbumin & nonpyramidal & $2-6$ & unknown & yes \\
Calbindin & pyramidal & $2 / 3$ & unknown & no \\
Calbindin & nonpyramidal & $2 / 3,5$ & unknown & yes \\
\hline Note that the & nypes &
\end{tabular}

Note that the types of neurons found specifically in layers $2-4$ of mammalian cortex are consistently absent from lizard and turtle cortex. The entry "unknown" indicates that definitive studies have not been done.

are found in all layers of the dorsal cortex and pallial thickening. Both the SP+ and LANT6+ nonpyramidal neurons in turtle cortex are similar in morphology to their mammalian counterparts.

Nonpyramidal neurons containing somatostatin (SS), neuropeptide Y (NPY) and GABA are present in all cellular layers of mammalian cortex, and the neurons are typically multipolar. All three of these substances are also observed in neurons throughout all layers in all parts of cortex in turtles, including PT (Bear and Ebner, 1983; Weindl, 1984; Blanton et al.,

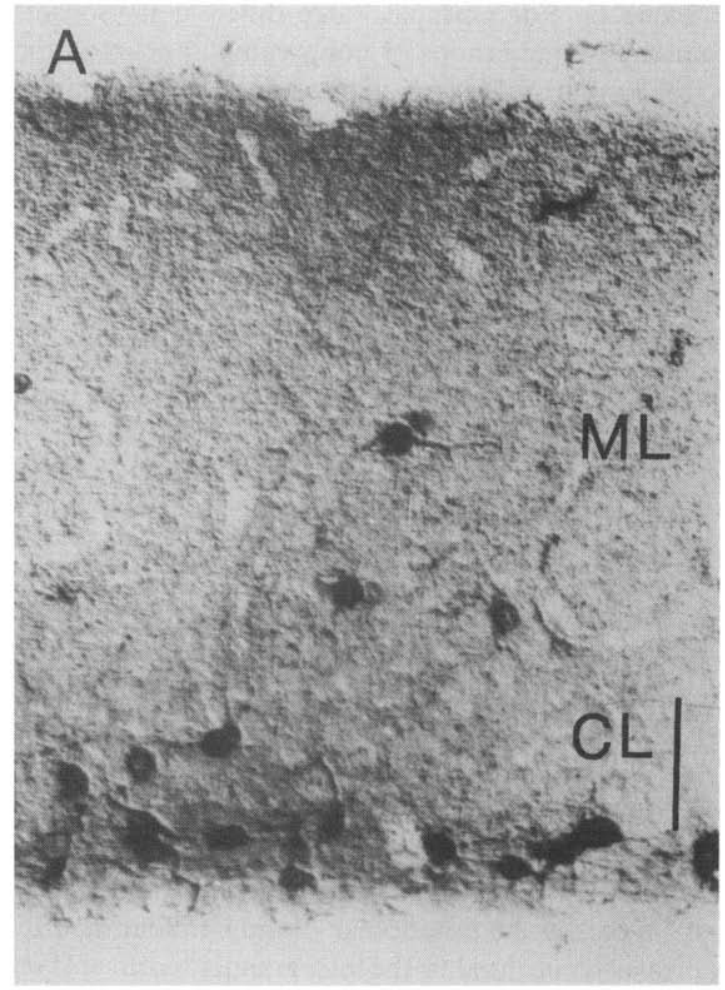

1987; Reiner, 1991). The SS +, NPY + and GABA + neurons all appear to be of the nonpyramidal type and are similar in size and morphology to their mammalian counterparts (Figs 4-5). Double-label studies have shown that SS and NPY are, in fact, extensively co-localized within the same individual neurons of turtle cortex (Reiner and Oliver, 1987). Extensive co-localization of SS and NPY in individual cortical neurons has also been reported for mammals (Vincent et al., 1982a,b). Based on findings in mammals and lizards, it seems likely that many of the

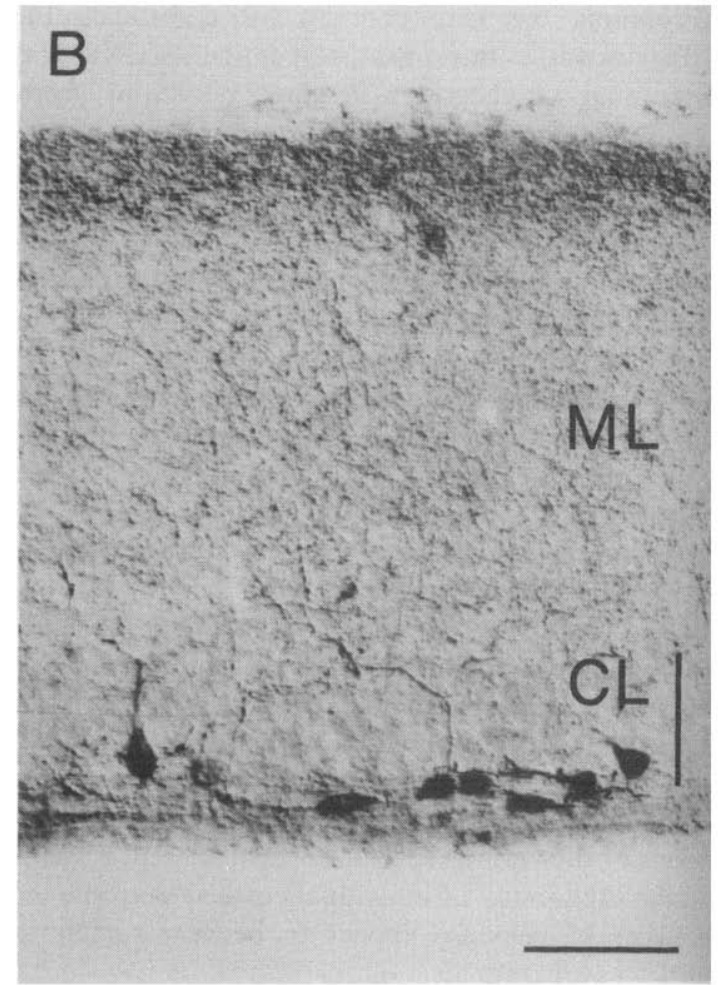

Fig. 4. Photomicrographs illustrating the morphology and laminar location of SS + (A) and NPY + (B) neurons in turtle dorsal cortex. Neurons of these types are present in all layers (ML, molecular layer; $C L$, cellular layer) of turtle cortex. The photomicrographs were taken using differential interference contrast microscopy. Scale bar: $B=100 \mu \mathrm{m} ; A=$ same magnification as in $B$. 


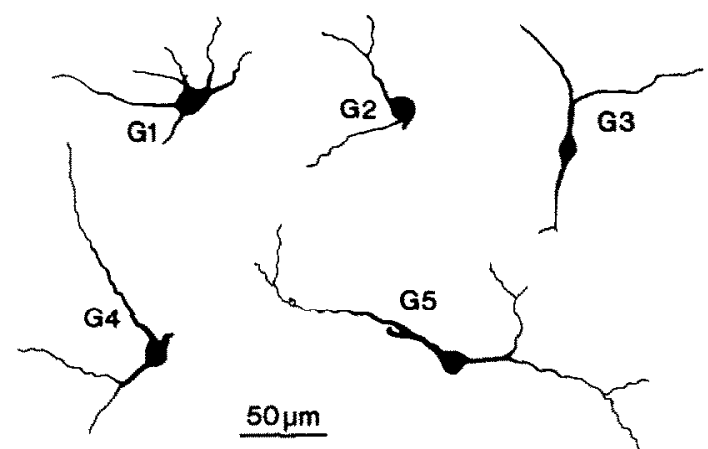

Fig. 5. Camera lucida drawings of GABAergic neurons of turtle dorsal cortex. Lateral is to the left for all drawings. The neurons G1-G5 were specifically located in the molecular layer. Others not shown here, but of a similar morphology, were observed in the cellular layer and in the subcellular layer. Although they show some variation in their dendritic morphology and perikarya size, these neurons typically possess a multipolar dendritic configuration resembling that of the nonpyramidal class of cortical neurons.

GABAergic cortical neurons in turtles also contain one or more neuropeptides (Jones and Hendry, 1986; Davila et al., 1991). For example, the SS+ and $\mathrm{NPY}+$ cortical neurons in turtles are likely to be a specific subpopulation of the GABAergic neurons. Similarly, other neuropeptides (LANT6, SP, ENK) may be found in other subpopulations of GABAergic neurons in turtle cortex.

Enkephalinergic cortical neurons in mammals are primarily located in the supragranular and infragranular layers (see Reiner, 1991). These ENK + neurons in mammals are small to medium-sized and tend to be bipolar or multipolar in their morphology. Two types of ENK + neurons are present in chelonian cortex and PT: neurons of a multipolar dendritic morphology, and neurons with a primarily radial dendritic tree that ascends toward the molecular layer (Reiner, 1991). The former are clearly nonpyramidal in their morphology, are most abundant in the cellular and subcellular layers of dorsal cortex and PT, and are reminiscent in their perikaryal size and shape of some ENK + perikarya observed in mammalian cortex. The other type of ENK + neurons have their perikarya in the cellular layer and possess a seemingly vertically disposed dendritic tree. This latter type of ENK + neuron may thus be pyramidal. Finally, glutamatergic neurons are widespread in mammalian cortex, particularly in the supra- and infragranular layers (see Reiner, 1991). These glutamatergic neurons in mammals appear to be pyramidal neurons that give rise to corticocortical and/or extracortical projections. In turtles, glutamatergic neurons are found in abundance in the cellular layer (Reiner, 1991). These glutamatergic neurons appear to give rise to a single, vertically-disposed primary dendrite. The dendritic morphology and location of these neurons is consistent with the possibility that they are pyramidal neurons.
The neurotransmitter-specific types of neurons found in the cortex of other reptilian groups (for example, lizards) are very similar to those found in turtles (Table 1). For example, SS +, NPY +, GABA + and LANT6 + neurons have all been found in cortex in lizards (Perez-Clausell and Fredens, 1988; Davila et al., 1991; Reiner, 1991; Martinez-Guijarro and Freund, 1992). In contrast, neither CCK8 + nor cholinergic nonpyramidal neurons of radial morphology have been found in lizard cortex (Perez-Clausell and Fredens, 1988; Reiner, 1991, 1992). Lizards do, however, appear to possess a population of cholinergic nonpyramidal cortical neurons that are absent in mammals and turtles (Hoogland and Vermeulen-VanderZee, 1990; Medina et al., 1993). The localization of VIP +, SP +, glutamatergic and enkephalinergic neurons in lizard cortex is uncertain (Perez-Clausell and Fredens, 1988; Reiner, 1991,1992). Three types of cortical neurons not yet studied in turtles but found in cortex in mammals have, however, been studied in lizard cortex. Two of these types contain the calcium binding protein calbindin, while the other contains the calcium binding protein parvalbumin. The two types of calbindin-containing neurons in mammalian isocortex are: pyramidal neurons restricted to layers $2-3$, and nonpyramidal neurons found in layers 2,3 and 5 . The parvalbumin-containing neurons in mammalian isocortex are all nonpyramidal. In lizards, nonpyramidal neurons containing both calbindin and parvalbumin have been described, while calbindincontaining pyramidal neurons are absent (MartinezGuijarro and Freund, 1992). Thus, lizard cortex also appears to lack the types of neurons found in layers 2-4 of mammalian cortex but possess those found in layers 5-6.

Connections of cortical neurons. Neurons containing VIP, CCK8 or CHAT are not the only types of neurons characteristic of granular and supragranular layers of mammalian cortex seemingly absent in turtles. Pathway tracing studies show that turtles also appear to entirely or largely lack the interregional and interhemispheric projection neurons characteristic of mammalian cortical layers 2-3 and lack the granular neurons characteristic of layer 4 of mammals (Ebner, 1976; Reiner, 1991). Similar results have been obtained in lizards (Voneida and Ebbesson, 1969; Lohman and Mentink, 1972; Butler, 1976; Bruce and Butler, 1984a,b; Hoogland and Vermeulen-VanderZee, 1989; Reiner, 1991). As noted above, the dorsal cortex of lizards and turtles does, however, possess a variety of features in terms of its inputs from and outputs to the basal forebrain, thalamus and brainstem that resemble those of layer 5-6 neurons of mammalian isocortex.

\section{Implications for turtle cortical organization and function}

These various findings on the anatomical and neurochemical organization of turtle cortex point to 
many similarities between turtles and mammals, but they also point to several noteworthy differences: (1) turtles lack the types of neurons characteristic of cortical layers $2-4$ in mammals; (2) turtles only possess the types of neurons present in cortical layers 5-6 in mammals; and (3) turtle cortex lacks columnar organization. It seems clear from these considerations that reptilian dorsal cortex must process information in a different way than do the corresponding regions of mammalian isocortex. In mammals, sensory thalamic input terminates heavily on neurons of layer 4 (Jones, 1981). These neurons, in turn, project to neurons in other layers within the same cortical column (Jones, 1981). Some of the neurons receiving input from layer 4 neurons (i.e. layer 2-3 neurons) also have projections within the same column, while neurons in deeper layers project to regions outside of cortex (Jones, 1981; Eccles, 1984). While the nature of the processing carried out within a column of isocortex is not precisely known, it seems clear that chelonian cortex would not be able to carry out as complex an operation as mammalian isocortex because chelonian cortex appears to lack the neuronal populations that underlie columnar organization. Further, in mammalian isocortex the individual axons of cortical afferent systems have terminations largely restricted to individual cortical columns (Jones, 1981; Rakic, 1988), thereby enabling thalamocortical projections to be topographically ordered. In contrast, thalamocortical afferent systems in turtles are not topographically ordered in a point to point fashion (Ulinski, 1988). Consistent with this anatomical observation, turtle visual cortex shows poor retinotopic organization and units in chelonian visual cortex show wide receptive fields (Belekhova, 1979; Ulinski, 1988). Thus, unlike in mammals, cortex in turtles does not appear to be capable of processing information about a discrete portion of the visual environment. For example, in mammals striate cortex appears to receive simple receptive field information about spots of light and dark in specific portions of the visual field and extract information regarding edges and line orientation in those portions of the visual field. It is difficult to imagine chelonian visual cortex performing much more than a simple operation whose outcome is a generalized response to global events in a large part of the visual field. This is consistent with the observation that lesions of visual dorsal cortex fail to affect visual discriminative performance in turtles but do affect learning processes (Cranney and Powers, 1983; Reiner and Powers, 1983; Grisham and Powers, 1984,1989) and with the suggestion by Ulinski (1988) that turtle dorsal cortex may be involved in a more global aspect of visual functions, possibly movement detection or attention. Thus, it appears likely that dorsal cortex in turtles plays a different role in information processing than does isocortex in mammals. It should be noted that these conclusions provide support for the idea that mammals may differ qualitatively from reptiles in some aspects of learning capacity (Hodos, 1982; Jerison, 1985; Macphail, 1982). It seems possible that mammals may be capable of some tasks requiring complex information processing and feature abstraction of which reptiles (or at least reptiles similar to turtles in brain organization) are incapable.

\section{Relationship of the dorsal cortex to the DVR}

The DVR in turtles and in nearly all other reptiles and in birds does not possess the laminar organization characteristic of the cortex. Rather, the DVR consists of a number of separate cell fields. In animals such as birds, with a very large and well-developed DVR, the DVR is more complex and consists of many more evident subdivisions than does the turtle DVR. The DVR's of birds and reptiles, however, do share a number of subdivisions in common, particularly those in receipt of visual and auditory input from the thalamus (Fig. 2). Both the DVR and dorsal cortex are clearly pallial derivatives and both are hodologically, histochemically and functionally similar to mammalian isocortex (Källen, 1951; Karten, 1969; Karten and Shimizu, 1990). The evolutionary relationship of DVR and dorsal cortex to each other and to isocortex, however, is not widely agreed upon. One school of thought is that both a DVR and dorsal cortex were present in stem reptiles ancestral to modern reptiles and mammals, and that the dorsal cortex and DVR both evolved into isocortex in the mammalian lineage (Karten, 1969). The considerable similarity of both dorsal cortex and DVR to isocortex in terms of connections, function and histochemistry favors this viewpoint. On the other hand, it is difficult to see how two structures so radically different in their cytoarchitecture as the DVR and dorsal cortex, could be transformed seamlessly into one structure of uniform cytoarchitecture, namely isocortex. Further, endocast data makes it dubious that early reptilian forerunners of mammals had as large and well-developed a DVR as even turtles (Hopson, 1979; Ulinski, 1983).

I wish to propose a slightly modified version of the ideas of Karten on the possible evolutionary relationships among the cortex and DVR of reptiles and the isocortex of mammals. There are three points of departure for my proposal. First, we have found that the turtle DVR (and the DVR of other reptiles as well) appears to lack the same neurotransmitterspecific cell types as turtle dorsal cortex (Mufson et al., 1984; Reiner et al., 1984b; Brauth et al., 1985; Reiner and Beinfeld, 1985; Reiner, 1987; Reiner and Oliver, 1987; Reiner, 1991, 1992). This observation suggests that reptilian DVR and reptilian dorsal cortex may have evolved from some common antecedent structure. Secondly, the dorsal cortex seems continuous with the lateral edge of the DVR via the pallial thickening, which is cytoarchitectonically a transitional zone between dorsal cortex and DVR. This suggests that in some antecedent reptiles, dorsal cortex, pallial thickening and DVR may have 
been continuous and possibly more cytoarchitectonically uniform. Finally, in one highly primitive living species of lizards, Sphenodon punctatum, the cytoarchitecture of the DVR and dorsal cortex may be that which is primitive for reptiles. In Sphenodon, the DVR does not consist of separate cell groups and there is no pallial thickening. Rather, the cell layer of the dorsal cortex continues around the lateral ventricle into the DVR and this cell layer then runs along the DVR in a periventricular position. Further, the DVR in Sphenodon is smaller than in any other living reptilian species. These various observations lead to the suggestion that perhaps in stem reptiles the dorsal cortex and DVR were identical in their cytoarchitecture, and the DVR was so poorly developed that it did not bulge into the ventricle (Figs 6,7). From this starting point, in which they were indistinguishable cytoarchitectonically, the DVR and dorsal cortex may have evolved along separate cytoarchitectonic paths from each other in the sauropsid lineage (Fig. 6), but evolved along the same cytoarchitectonic path as each other in the mammalian lineage (Fig. 7). Residual evidence of the once cortex-like laminar structure of the DVR in stem reptiles may still manifest itself as the corticoid periventricular cell plate of the DVR observed in turtles and type I lizards (i.e., lizards with a more primitive DVR structure) (Northcutt, 1978; Ulinski, 1983) and as the continuous cell layer of the DVR and cortex in Sphenodon punctatum (Durward, 1930).

Although this proposal is speculative, it does account for the similarities between reptilian dorsal cortex compared to reptilian DVR on one hand and between reptilian dorsal cortex and DVR compared to mammalian isocortex on the other. One interesting topographic comparison further favors this current speculation. Note that the DVR in reptiles is basically an involuted piece of pallium (Figs 6,7). If it were projected back out onto the pallial surface (dorsomedial to the rhinal fissure), then four contiguous functional areas would be present: (1) a geniculorecipient visual area most dorsal (VI); (2) an extrastriate tectothalamorecipient visual area lateral to the geniculocortical area (V2); (3) an auditory area lateral to the extrastriate visual area and abutting the olfactory cortex laterally; and (4) a somatosensory area rostral to the geniculorecipient cortical area (shown in Fig. 2). These same four areas are present in the brains of most primitive mammals (e.g. platypus, insectivores and marsupials such as opossums) in the same topological sequence (compare 6D and 7D) and in the same relationship to olfactory cortex (Diamond and Hall, 1969; Ebner, 1969; Lende, 1969; Sanides, 1969; Bohringer and Rowe, 1977). This topological commonality could possibly refiect that all four sensory areas plus olfactory cortex were present in the telencephalon of stem reptiles and evolved along separate paths in the sauropsid and mammalian lineages. The next section will more specifically address the cytoarchitectonic alteration that may have accompanied the evolution of reptilian three-layered cortex into at least parts of mammalian cerebral isocortex, focusing mainly on the dorsal cortex. It is possible that the same alterations may have occurred in the evolution of the putative three layers of the proto-DVR of stem reptiles into the other parts of mammalian isocortex.

\section{Implications for the evolution of mammalian isocortex}

Since reptilian dorsal cortex possesses few functionally distinct regions (as also appears true for other living reptiles), it seems likely that the pro-isocortex of early mammal-like reptiles possessed correspondingly few functionally-distinct regions (Allman, 1990; Reiner, 1991). Even the isocortex of simpler mammals (such as the platypus, insectivores and some marsupials), however, which consists of few cortical areas, is histologically more cell-rich and complex than the dorsal cortex of any reptile. Although many investigators have identified dorsal cortex as containing the homologues of at least some isocortical regions in mammals, few have attempted to account for the cytoarchitectural differences between reptile cortex and mammalian isocortex in any detailed way (Elliot-Smith, 1919; Dart, 1934; Ariëns-Kappers et al., 1936; Hall et al., 1977; Northcutt, 1970; Ebner, 1976). The overall data on turtle dorsal cortex reviewed here suggest that dorsal cortex lacks the neuronal populations characterizing layers 2-4 of mammalian isocortex. In contrast, dorsal cortex in turtles does appear to possess the cell types characterizing layers 5-6 of mammalian isocortex. Based on the available data, the results in turtles appear to be similar to those in other reptiles and to those in amphibians, and to some extent those in birds (see Reiner, 1991). Thus, the absence from the dorsal cortex (and pallial thickening) of turtles of the neuronal cell types corresponding to those of isocortical layers $2-4$ in mammals appears to be a pervasive condition for this telencephalic region among living amphibians, reptiles and birds and therefore appears to represent the primitive pattern for land vertebrates. Consequently, the presence of these cell types in mammals appears to reflect the acquisition of these cell types in the lineage leading from reptiles to mammals. Thus, the present findings, in conjunction with previously published findings, suggest the hypothesis that mammalian isocortex evolved from reptilian dorsal cortex with the addition of new cell types, namely those characterizing layers 2-4 of isocortex (Fig. 8). Some previous authors have come to generally similar conclusions on the evolution of mammalian isocortex from reptilian cortex as reached here (Ebner, 1976; Marin-Padilla, 1978, 1988; Morgane et al., 1985, 1986; Glezer et al., 1988).

This conclusion requires that a number of specific changes occurred to transform early reptilian dorsal cortex into mammalian isocortex. Among these events were the proliferation and specification of new 
HYPOTHESIZED STEM REPTILE

A
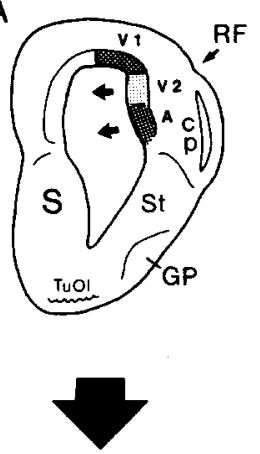

B

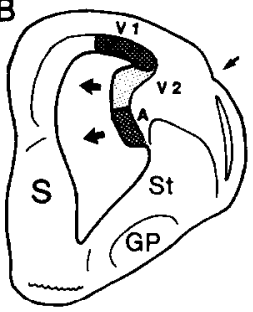

HYPOTHESIZED

EARLY SAUROPSID
TURTLE GRADE
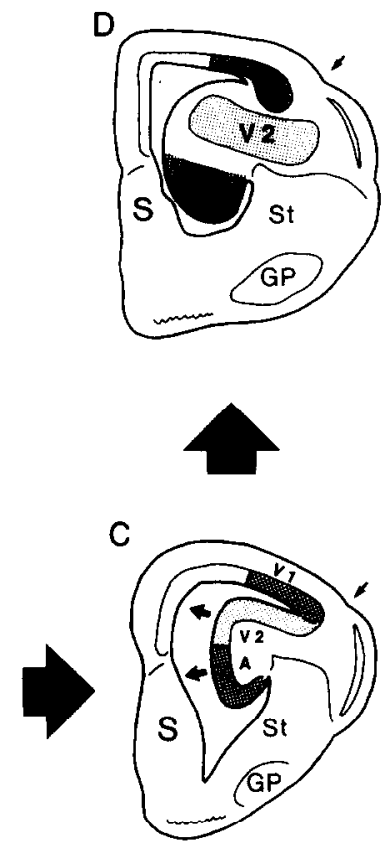

HYPOTHESIZED

LATER SAUROPSID: SPHENODON GRADE

Fig. 6. Proposed evolution of the DVR from a hypothesized ancestral proto-DVR condition (in which the DVR does not bulge into the ventricle) in the earliest reptiles $(A)$, to a hypothesized early stage of DVR enlargement in the earliest (now extinct) sauropsids (early in the lineage leading to modern reptiles and birds) (B), to a Sphenodon grade at a later point in early sauropsid evolution (C), and finally to a turtle grade (D). All schematic drawings are of transverse sections through the telencephalon at the level of the anterior commissure. In constructing this hypothesis, it was assumed that distinct V1 visual, V2 visual and auditory regions were already present in the pallium of stem reptiles and that the cells of the proto-DVR and cortex in stem reptiles were both in a periventricular position. This assumption makes it possible to account for the topological similarities in these sensory areas that are evident between modern reptiles and mammals (compare 6D and 7D) and to account for the organization of the DVR in Sphenodon compared to other reptiles. The evolutionary changes in the proto-DVR leading to the early sauropsid and Sphenodon grades are assumed to consist mainly of enlargement of the DVR and its ingrowth into the ventricle. Finally, the changes in the DVR from the Sphenodon to the turtle grade consisted of cytodifferentiation of the DVR and pallial thickening into non-periventricular cell groups. The arrows within the ventricle in $\mathrm{A}-\mathrm{C}$ indicate the direction of growth of the DVR cell mass. Note that the schematic of the Sphenodon grade is not meant to be a rendering of a section through the telencephalon of Sphenodon punctatum but is meant to represent a hypothetical Sphenodon-like grade of reptilian telencephalic evolution. Abbreviations: A, auditory region; cp, pyriform (olfactory) cortex; GP, globus pallidus; $\mathbf{R F}$, rhinal fissure (indicated by arrows in B, C and D); $\mathbf{S}$, septal region; St, striatum; V1, primary visual area; V2, secondary visual area; TuOl, olfactory tubercle.

HYPOTHESIZED

STEM REPTILE

RODENT GRADE

A
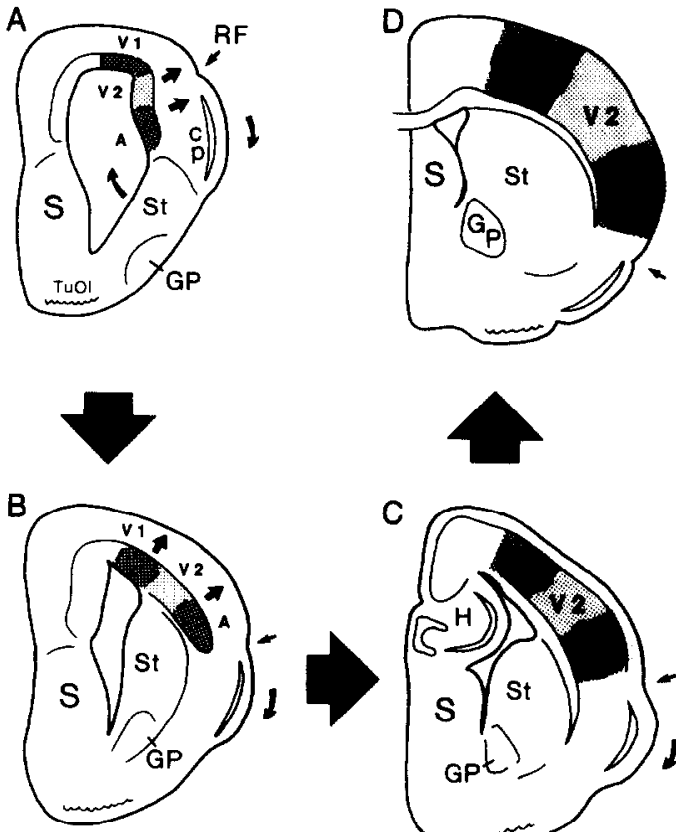

C

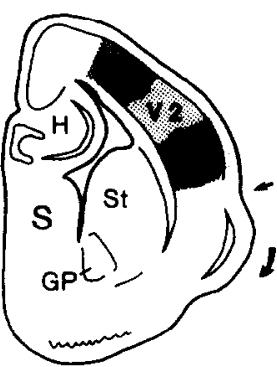

HYPOTHESIZED

EARLY MAMMAL-LIKE REPTILE
HYPOTHESIZED

EARLY MAMMAL: MARSUPIAL GRADE

Fig. 7. Proposed evolution of the isocortex from a hypothesized ancestral proto-DVR condition (in which the DVR does not bulge into the ventricle) in the earliest reptiles (A), to a hypothesized early stage of cortical expansion and translocation in the earliest mammal-like reptiles (therapsids) (B), to a marsupial grade at a later point in early mammalian evolution (C), and finally to a rodent (simple mammal) grade (D). All schematic drawings are of transverse sections through the telencephalon at the level of the anterior commissure. In constructing this hypothesis, it was assumed that distinct $\mathrm{V} 1$ visual, V2 visual and auditory regions were already present in the pallium of stem reptiles and that the cells of the proto-DVR and cortex in stem reptiles were both in a periventricular position. This assumption makes it possible to account for the topological similarities in these sensory areas that are evident between modern reptiles and mammals (compare 6D and 7D) and to account for the seamless transformation of both the reptilian cortex and reptilian proto-DVR into mammalian isocortex by the addition of layer 2-4 cell types. The evolutionary changes in the proto-DVR leading to the therapsid grade are assumed to consist mainly in the shift of the positions of the cortical plate, the basal ganglia and the pyriform cortex (direction of shifts shown by arrows in A). The further changes from the therapsid to the marsupial grade are assumed to consist mainly of thickening and differentiation of the cortical plate, presumably accompanied by the addition of the layer 2-4 cell types, and the further ventralward shift of the olfactory cortex (see arrow in B). Finally, the changes in the isocortex from the marsupial to the rodent grade consist mainly of the expansion and further laminar differentiation of the isocortex, and the further ventralward shift of the olfactory cortex (see arrow in $\mathrm{C}$ ). Abbreviations: A, auditory region; cp, pyriform (olfactory) cortex; GP, globus pallidus; $\mathbf{H}$, hippocampal complex; RF, rhinal fissure (indicated by arrows in B, C and D); $S$, septal region; St, striatum; V1, primary visual area; V2, secondary visual area; TuOl, olfactory tubercle. 

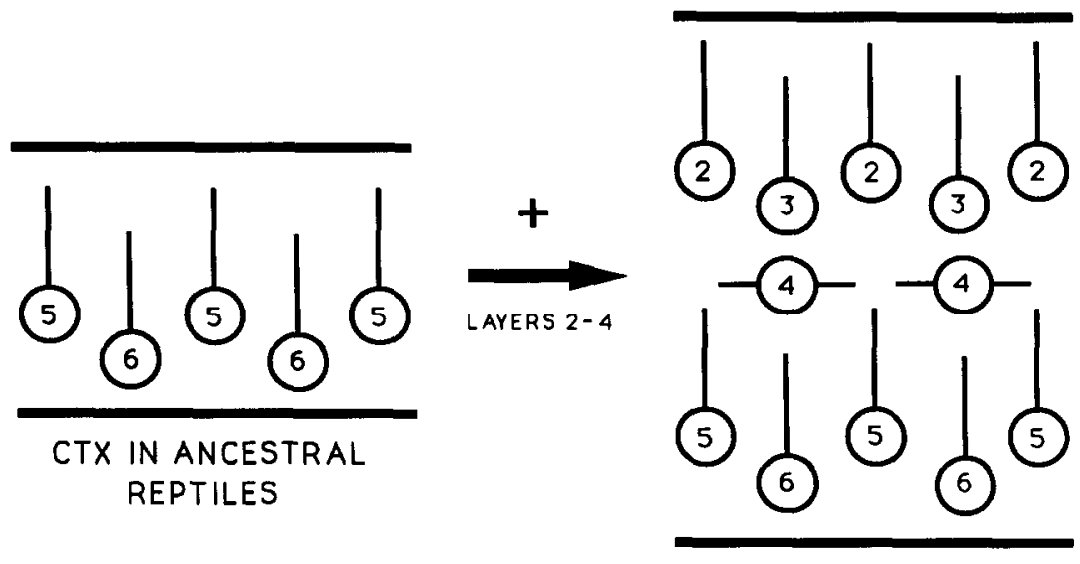

MAMMALIAN CTX

Fig. 8. Schematic illustrating the present conclusion on the evolution of cortex (CTX) in the lineage leading from ancestral reptiles to modern mammals. The data reviewed are consistent with the conclusion that only neurons homologous to neurons in isocortical layers 5 and 6 were present in the dorsal cortex of the reptiles ancestral to mammals. The evolution of mammalian isocortex therefore must have entailed the addition of the neurons of layers $2-4$ in the reptile-mammal lineage, with the segregation of these various old and new neuronal types into distinct lamina.

neuronal types, and the elaboration of the laminar and columnar organization of cortex. These changes apparently occurred in extinct mammal-like reptiles, since isocortex is six-layered, possesses the same basic cell types (except perhaps for layer 4 granule cells in some mammals) and is columnar in its organization in all mammals. Further, there has been a clear trend within various mammalian orders toward an increase in cortical surface area and an increase in the number of functionally defined areas of isocortex. As noted above, among "primitive" living mammals such as insectivores, marsupials and monotremes, a somatosensory region, two visual regions and an auditory region are typically present (Diamond and Hall, 1969; Lende, 1969; Nauta and Karten, 1970; Diamond, 1976; Bohringer and Rowe, 1977; Johnson, 1977; Morgane et al., 1986; Kaas, 1989). Thus, as few as four distinct sensory/motor areas may have been present in the mammals ancestral to modern mammals. As discussed earlier, dorsal cortex in turtles contains a rostrally situated somatosensory area and a visual area (V1) immediately caudal to this somatosensory area (Johnston, 1915, 1916; Orrego, 1961; Hall et al., 1977). The DVR in turtles and other reptiles contains both an extrastriate visual area (V2) and an auditory area (Lohman and van WoerdenVerkley, 1978; Pritz, 1980; Balaban, 1981; Brucc and Butler, 1984a,b). Given the apparent ubiquity of an auditory area in the DVR, a primary visual area in the dorsal cortex and an extrastriate visual area in the DVR among living reptiles, it seems plausible that these were also present in ancestral reptiles. If one assumes that a somatosensory area was also present in ancestral reptiles, it is intriguing to note that the number and identity of sensory areas primitive for reptiles corresponds to that seemingly primitive for mammals. It is reasonable to expect that the ancestral mammals may have inherited at least their so- matosensory and primary visual areas from the ancestral reptiles. Concluding that the auditory and visual areas of ancestral mammals were reptilian inheritances, however, requires one to assume that the DVR of reptiles is homologous to some portions of mammalian isocortex, which is a plausible assumption as noted above. Although some authors have stated their support for such a conclusion (Karten, 1969; Nauta and Karten, 1970; Karten and Shimizu, 1990; Ulinski, 1990; Ulinski and Margoliash, 1990), others have argued against such a conclusion (Northcutt, 1978, 1981; Ulinski, 1983). Regardless of whether ancestral mammals inherited two cortical areas (somatosensory and primary visual) or four cortical areas (somatosensory, primary visual, extrastriate visual and auditory) from ancestral reptiles, it is important to note that the transition from a reptilian grade of organization to a mammalian grade of organization may not have been accompanied by an increase in the number of cortical areas (Allman, 1990; Reiner, 1991). Cortical expansion and increase in the number of cortical areas has clearly occurred in a number of mammalian lineages after the evolutionary attainment of a six-layered cytoarchitecture (Lende, 1969; Glezer et al., 1988; Kaas, 1989; Allman, 1990).

\section{Value of studies of turtle dorsal cortex}

Studies of dorsal cortex in turtles help clarify the role this structure plays in the behavior of turtles and other reptiles and help clarify the cellular and neural basis of that role. Studies of dorsal cortex in turtles also help shed light on the evolution of mammalian isocortex. The available studies thus far indicate that turtle dorsal cortex shares many similarities with mammalian isocortex, but seems to correspond most closely to layers 5-6 of mammalian cortex. Thus, anatomical and physiological studies of turtles cortex 
could shed light on the neurotransmitter and synaptic mechanisms underlying interneuronal communication in cortex, at least those having to do with fundamental processing occurring in infragranular cortex (Connors and Kriegstein, 1986; Kriegstein and Connors, 1986; Larson-Prior et al., 1991). One particularly exciting area of synaptic physiology in which study of turtle cortex could be useful is ischemia. Ischemic neuronal cell death is now known to be the consequence of excitotoxicity mediated by glutamate receptors (Choi, 1988). This type of cell death is a major contributor to the neuronal damage occurring with heart attack, stroke or any other event interfering with the neural vascular supply. Turtle cortex, however, appears to be extremely resistant to ischemic neuronal death, at least in aquatic turtles (Wilson and Kriegstein, 1989). Elucidating the basis of the unique resistance of turtle cortex to ischemia may provide clues for combating ischemic neuronal death in humans (Young et al., 1990). Finally, turtle nervous system in general is a favorable model for neurophysiological study because it readily lends itself to use as an extremely durable in vitro preparation (Connors and Kriegstein, 1986; Kriegstein and Connors, 1986; Larson-Prior et al., 1991).

Acknowledgements - I would like to thank Drs Harvey J. Karten, Steven E. Brauth and R. Glenn Northcutt for their helpful and seminal discussions with me on the topic of this paper over the years. In particular the proto-DVR hypothesis is an outgrowth of discussions that Steve Brauth and I have had over the years. The research from my laboratory presented here has been supported by NS-19620, NS-28721 and EY-05298 (A.R.).

\section{REFERENCES}

Allman J. (1990) Evolution of Neocortex. In Cerebral Cortex, Evolution and Comparative Anatomy of Cerebral Cortex. Part I ( Edited by Jones E. G. and Peter A.), Vol. 8A, pp. 269-283. Plenum Press, NY.

Ariëns Kappers C. U., Huber G. C. and Crosby E. C. (1936) The Comparative Anatomy of the Nervous System of Vertebrates, Including Man. Reprinted 1960. Hafner, New York.

Balaban C. D. (1981) Organization of thalamic afferents to anterior dorsal ventricular ridge in turtles: 1 . Projection of thalamic nuclei. J. comp. Neurol. 200, 95-130.

Bear M. F. and Ebner F. F. (1983) Somatostatin-like immunoreactivity in the forebrain of Pseudemys turtles. Neuroscience 9, 297-307.

Belekhova M. G. (1979) Neurophysiology of the forebrain. In Biology of the Reptilia. Neurology B. (Edited by Gans C., Northcutt R. G. and Ulinski P. S.), Vol. 10, pp. 287-359. Academic Press, NY.

Blanton M. G., Shen J. M. and Kriegstein A. R. (1986) Actions of acetylcholine in turtle dorsal cortex. Soc. Neurosci. Abs. 12, 573.

Blanton M. G., Shen J. M. and Kriegstein A. R. (1987) Evidence for the inhibitory neurotransmitter $\gamma$-aminobutyric acid in aspiny and sparsely spiny nonpyramidal neurons of the turtle dorsal cortex. J. comp. Neurol. 259, 277-297.

Bohringer R. C. and Rowe M. J. (1977) The organization of the sensory and motor areas of cerebral cortex in the platypus (Ornithorhynchus anatinus). J. comp. Neurol. 174, $1-14$.
Brauth S. E., Kitt C. A., Price D. L. and Wainer B. H. (1985) Cholinergic neurons in the telencephalon of the reptile Caiman crocodilus. Neurosci. Lett. 58, 235-240.

Bruce L. L. and Butler A. B. (1984a) Telencephalic connections in lizards. I. Projections to cortex. J. comp. Neurol. 229, 585-601.

Bruce L. L. and Butler A. B. (1984b) Telencephalic connections in lizards. II. Projections to anterior dorsal ventricular ridge. J. comp. Neurol. 229, 602-615.

Butler A. B. (1976) Telencephalon of the lizard Gekko gecko (Linnaeus): Some connections of the cortex and dorsal ventricular ridge. Brain Behav. Evol. 13, 396-417.

Choi D. W. (1988) Glutamate neurotoxicity and diseases of the nervous system. Neuron 1, 623-634.

Connors B. W. and Kriegstein A. R. (1986) Cellular physiology of the turtle visual cortex: distinctive properties of pyramidal and stellate neurons. $J$. Neurosci. 6, 164-177.

Cranney J. and Powers A. S. (1983) The effects of core nucleus and cortical lesions in turtles on reversal and dimensional shifting. Physiol. Psych. 11, 103-111.

Dart R. A. (1934) The dual structure of the neopallium: its history and significance. J. Anat. (London) 69, 1-19.

Davila J. C., Guirado S., de la Calle A. and Marin-Giron F. (1986) Ultrastructure of the dorsal cortex of the lizard Psammodromus algirus. J. Hirnforsch 27, 295-304.

Davila J. C., de la Calle A., Gutierrez A., Megias M., Andreu M. J. and Guirado S. (1991) Distribution of neuropeptide Y (NPY) in the cerebral cortex of the lizards Psammodromus algirus and Podarcis hispanica: Co-localization of NPY, somatostatin and GABA. J. comp. Neurol. 308, 397-408.

Diamond I. T. (1976) Organization of the visual cortex: comparative anatomical and behavioral studies. Fed. Proc. 35, 60-67.

Diamond I. T. and Hall W. C. (1969) Evolution of neocortex. Science 164, 251-262.

Durward A. (1930) The cell masses in the forebrain of Sphenodon punctatum. J. Anat. 65, 8-44.

Ebbesson S. O. E. and Voneida T. J. (1969) The cytoarchitecture of the pallium in the tegu lizard (Tupinambis nigropunctatus). Brain Behav. Evol. 2, 431-466.

Ebner F. F. (1969) A comparison of primitive forebrain organization in metatherian and eutherian mammals. Ann. N.Y. Acad. Sci. 167, 241-257.

Ebner F. F. (1976) The forebrain of reptiles and mammals. In Evalution of Brain and Behavior in Vertebrates (Edited by Masterton R. B., Bitterman M. E., Campbell C. B. G. and Hotton N.), pp 147-167. J. Wiley and Sons, NY.

Eccles J. C. (1984) The cerebral cortex. A theory of its operation. In Cerebral Cortex. Functional Properties of Cortical Cells (Edited by Jones E. G. and Peters A., Vol. II, pp. 1-36. Plenum Press, NY.

Elliot Smith G. (1919) A preliminary note on the morphology of the corpus striatum and the origin of the neopallium. J. Anat. 53, 271-291.

Glezer I.I., Jacobs M. S. and Morgane P. J. (1988) Implications of the "initial brain" concept for brain evolution in Cetacea. Behav. Brain Sci. 11, 75-116.

Grisham W. and Powers A. S. (1984) Differential effects of medial and dorsal cortex lesions on spatial reversals in turtles (Chrysemys picta). Soc. Neurosci. Abs. 10, 131.

Grisham W. and Powers A. S. (1989) Function of the dorsal and medial cortex in learning. Behav. Neurosci. 103, 991-997.

Guirado S., Davila J. C. de la Calle A. and Marin Giron F. (1987) A Golgi study of the dorsal cortex in the lizard Psammodromus algirus. J. Morphol. 194, 265-274.

Hall J. A., Foster R. E., Ebner F. F. and Hall W. C. (1977) Visual cortex in a reptile, the turtle (Pseudemys scripta and Chrysemys picta). Brain Res. 130, 197-216.

Hodos W. (1982) Some perspectives on the evolution of intelligence and the brain. In Animal Mind-Human Mind 
(Edited by Griffin D. R.), pp. 34-55. Dahlem Konferenzen, Springer-Verlag, NY.

Hoogland P. V. and Vermeulen-VanderZee E. (1989) Efferent connections of the dorsal cortex of the lizard Gekko gecko studied with Phaseolus vulgaris-Leucoagglutinin. J. comp. Neurol. 285, 289-303.

Hoogland P. V. and Vermeulen-VanderZee E. (1990) Distribution of choline acetyltransferase immunoreactivity in the telencephalon of the lizard Gekko gecko. Brain Behav. Evol. 6, 378-390.

Hopson J. A. (1979) Paleoneurology. In Biology of the Reptilia (Edited by Gans C., Northcutt R. G. and Ulinski P.), Vol. 9, pp. 39-146. Academic Press, N.Y.

Jerison H. J. (1985) Animal intelligence as encephalization. Phil. Trans. R. Soc. Lond. 308, 21-35.

Johnson, J. I. (1977) Central nervous system of marsupials. In The Biology of Marsupials (Edited by Hunsaker A.), pp. 159-278. Academic Press, N.Y.

Johnston J. P. (1915) The cell masses in the forebrain of the turtle, Cistudo carolina. J. comp. Neurol. 25, 393-468.

Johnston J. P. (1916) Evidence of a motor pallium in the forebrain of reptiles. $J$ comp. Neurol. 26, 475-479.

Jones E. G. and Hendry S. H. C. (1986) Co-localization of GABA and neuropeptides in neocortical neurons. Trends Neurosci. 9, 71-76.

Jones E. G. (1981) Anatomy of cerebral cortex: columnar input-output organization. In The Organization of the Cerebral Cortex (Edited by Schmitt F. O., Worden, F., Adelman G. and Dennis S. G.), pp. 199-235. MIT Press, Cambridge, MA

Jones E. G., DeFelipe J., Hendry S. H. C. and Maggio J. E. (1988) A study of tachykinin-immunoreactive neurons in monkey cerebral cortex. J. Neurosci. 8, 1206-1224.

Kaas J. H. (1989) The evolution of complex sensory systems in mammals. J. exp. Biol. 146, 165-176.

Källén B. (1951a) Embryological studies on the nuclei and their homologization in the vertebrate forebrain. K. Fysiogr. Saellsk. Handl. 62, 1-36.

Karten H. J. (1969) The organization of the avian telencephalon and some speculations on the phylogeny of the amniote telencephalon. In Comparative and Evolutionary Aspects of the Vertebrate Central Nervous System (Edited by Noback C. and Petras J.), Ann. N.Y. Acad. Sci. 167, 146-179.

Karten H. J. and Shimizu T. (1990) The origins of neocortex: connections and lamination as distinct events in evolution. J. Cognitive Sci. 1 291-301.

Kriegstein A. R. and Connors B. W. (1986) Cellular physiology of the turtle visual cortex: synaptic properties and intrinsic circuitry. J. Neurosci. 6, 178-191.

Larson-Prior L. J., Ulinski P. S. and Slater N. T. (1991) Excitatory amino acid receptor-mediated transmission in geniculocortical and intracortical pathways within visual cortex. J. Neurophys. 66, 293-306.

Lende R. A. (1969) A comparative approach to the neocortex: localization in monotremes, marsupials and insectivores. Ann. N.Y. Acad. Sci. 167, 262-276.

Lohman A. H. M. and Mentink G. M. (1972) Some cortical connections of the Tegu lizard (Tupinambis teguixin). Brain Res. 45, 325-344.

Lohman A. H. M. and van Woerden-Verkley I. (1978) Ascending connections in the forebrain of the Tegu lizard (Tupinambis teguixin). J. cump. Neurol. 82, 555-594.

Lund J. S. (1984) Spiny stellate cells. In Cerebral Cortex. Cellular Components of the Cerebral Cortex (Edited by Peters A. and Jones E. G.), Vol. 1, pp 255-308. Plenum Press, NY.

Macphail E. M. (1982) Brain and Intelligence in Vertebrates. Clarendon Press, Oxford.

Marin-Padilla M. (1978) Dual origin of the mammalian neocortex and evolution of the cortical plate. Anat. Embryol. 152, 109-126.

Marin-Padilla M. (1988) Early ontogenesis of the human cerebral cortex. In Cerebral Cortex. Development and Maturation of Cerebral Cortex (Edited by Peters A. and Jones E. G.), Vol. 7, pp 1-34. Plenum Press, NY.

Martinez-Guijarro F. J. and Freund T. F. (1992) Distribution of GABAergic interneurons immunoreactive for calretinin, calbindin D28K, and parvalbumin in the cerebral cortex of the lizard Podarcis hispanica. J. comp. Neurol. 322, 449-460.

Medina L., Smeets W. J. A. J., Hoogland P. V. and Puelles L. (1993) Distribution of choline acetyltransferase immunorecativity in the brain of the lizard Gallotia galloti. J. comp. Neurol. (submitted).

Morgane P. J., Jacobs M. S. and Galaburda A. M. (1985) Conservative features of neocortical evolution in dolphin brain. Brain Behav. Evol. 26, 176-184.

Morgane P. J., Jacobs M. S. and Galaburda A. (1986) Evolutionary morphology of the dolphin brain. In Dolphin Cognition and Behavior: A Comparative Approach (Edited by Schusterman R. Wood F. and Thomas J.), pp 5-29. Erlbaum Association, NJ.

Mufson E. J., Desan P. H., Mesulam M. M., Wainer B. H. and Levey A. I. (1984) Choline acetyltransferase-like immunoreactivity in the forebrain of the red-eared pond turtle (Pseudemys scripta elegans). Brain Res. 323, 103-108.

Nauta W. J. H. and Karten H. J. (1970) A general profile of the vertebrate brain, with sidelights on the ancestry of cerebral cortex. In The Neurosciences: Second Study Program (Edited by Schmitt F. O.), pp 7-26. The Rockefeller University Press, NY.

Northcutt R. G. (1970) The Telencephalon of the Western Painted Turtle (Chrysemys picta belli). Univ. Illinois Press, Urbana, IL.

Northcutt R. G. (1978) Forebrain and midbrain organization in lizards and its phylogenetic significance. In Behavior and Neurology of Lizards (Edited by Greenberg N. and MacLean P. D.), pp. 11-64. NIMH, Rockville, MD.

Northcutt R. G. (1981) Evolution of the telencephalon in nonmammals. A. Rev. Neurosci. 4, 301-350.

Orrego F. (1961) The reptilian forebrain. I. The olfactory pathways and cortical areas in the turtle. Arch. Ital. Biol. 99, 425-445.

Ouimet C. C., Patrick R. L. and Ebner F. F. (1985) The projection of three extrathalamic cell groups to the cerebral cortex of the turtle Pseudemys. J. comp. Neurol. 237. $77-84$.

Parent A. (1973) Distribution of monoamine-containing nerve terminals in the brain of the painted turtle, Chryse mys picta. J. comp. Neurol. 148, 153-166.

Parent A. and Poitras D. (1974) The origin and distribution of catecholaminergic axon terminals in the cerebral cortex of the turtle (Chrysemys picta). Brain Res. 78, 345-358.

Perez-Clausell J. and Fredens K. (1988) Chemoarchitectonics in the telencephalon of the lizard Podarcis hispanica. Distribution of somatostatin, enkephalin, cholecystokinin and zinc. In The Forebrain of Reptiles. Current Concepts of Structure and Function (Edited by Schwerdtfeger W. K. and Smeets W. J. A. J.), pp. 85-96. Karger, Basel.

Pritz M. B. (1980) Parallels in the organization of auditory and visual systems in crocodiles. In Comparative Neurology of the Telencephalon (Edited by Ebbesson S. O. E.), pp. 331-342. Plenum Press. NY.

Rakic P. (1988) The specification of cerebral cortical areas. Science 241, 170-241.

Reiner A. (1987) The distribution of proenkephalin-derived peptides in the central nervous system of turtle. J. comp. Neurol. 259, 65-91.

Reiner A. (1991) A comparison of the neurotransmitterspecific and neuropeptide-specific neuronal cell types present in turtle cortex to those present in mammalian isocortex: implications for the evolution of isocortex. Brain Behav. Evol. 38, 53-91. 
Reiner A. (1992) Neuropeptides in the nervous system. In Sensorimotor Integration. Biology of the Reptilia (Edited by Gans C. and Ulinski P. S.) Vol. 17, pp. 587-739. Univ. of Chicago Press, IL.

Reiner A. and Anderson K. D. (1990) The patterns of neurotransmitter and neuropeptide co-occurrence among striatal projection neurons: conclusions based on recent findings. Brain Res. Rev. 15, 251-265.

Reiner A. and Beinfeld M. C. (1985) The distribution of cholecystokinin-8 in the central nervous system of turtles: an immunohistochemical and biochemical study. Brain Res. Bull. 15, 167-181.

Reiner A. and Oliver J. R. (1987) Somatostatin and neuropeptide $\mathrm{Y}$ are almost exclusively found in the same neurons in the telencephalon of turtles. Brain Res. 426, 149-156.

Reiner A. and Powers A. S. (1983) The effects of lesions of telecephalic visual structures on the visual discriminative performance of turtles (Chrysemys picta picta). J. comp. Neurol. 218. 1-24.

Reiner A., Brauth S. E. and Karten H. J. (1984a) Evolution of the amniote basal ganglia. Trends Neurosci. 7, 320-325.

Reiner A., Krause J. E., Keyser K. T., Eldred W. D. and McKelvy J. F. (1984b) The distribution of substance $P$ in turtle nervous system: an immunohistochemical and radioimmunoassay study. $J$. comp. Neurol. 226, 50-75.

Reiner A., Eldred W. D., Beinfeld M. C. and Krause J. E. (1985) The co-occurrence of a substance P-like peptide and cholecystokinin-8 in a fiber system of turtle cortex. J. Neurosci. 5, 15271544.

Sanides F. (1969) Comparative architectonics of the neocortex of mammals and their evolutionary interpretation. Ann. N.Y. Acad. Sci. 167, 404-423.

Schlegel J. R., Peroutka S. J. and Kriegstein A. R. (1986) Autoradiographic demonstration of benzodiazepine and muscarinic receptors in turtle cortex. Soc. Neurosci. Abs. $12,1189$.

Shen J. M. and Kriegstein A. R. (1986) Serotonin inhibits spontaneous neuronal activity in turtle dorsal medial cortex. Soc. Neurosci. Abs. 12, 574.

Smith L. M., Ebner F. F. and Colonnier M. (1980) The thalamocortical projection in Pseudemys turtles: a quantitative electron microscopic study. J. comp. Neurol. 190 , 445-461.

Szentagothai J. (1978) The neuron network of the cerebral cortex. Proc. R. Soc. Lond. B. 201, 219-248.
Szentagothai J. (1983) The modular architectonic principle of neural centers. Rev. Physiol. Biochem. Pharmac. 98, 11 $-61$.

Ulinski P. S. (1974) Cytoarchitecture of cerebral cortex in snakes. J. comp. Neurol. 158, 243-266.

Ulinski P. S. (1983) Dorsal Ventricular Ridge. A Treatise on Forebrain Organization in Reptiles and Birds. John Wiley and Sons, NY.

Ulinski P. S. (1986) Organization of corticogeniculate projections in the turtle, Pseudemys scripta. J. comp. Neurol. 254, 529-542.

Ulinski P. S. (1988) Functional architecture of turtle dorsal cortex. In The Forebrain of Reptiles. Current Concepts of Structure and Function (Edited by Schwerdtfeger W. K. and Smeets W. J. A. J.), pp. 151-161. Karger, Basel.

Ulinski P. S. (1990) Nodal events in forebrain evolution. In: Proceedings of the Third International Congress of Vertebrate Brain Morphology. Netherlands J. Zool. (in press.)

Ulinski P. S. and Margoliash D. (1990) Neurobiology of the reptile-bird transition. In Cerebral Cortex, Evolution and Comparative Anatomy of Cerebral Cortex (Edited by Jones E. G. and Peters A.), pp. 217-264. Plenum Press, NY.

Vincent S. R., Johansson O. Hokfelt T., Meyerson B., Sachs C., Elde R. P., Terenius L. and Kimmel J. (1982a) Neuropeptide co-existence in human cortical neurons. Nature, 298, 65-67.

Vincent S. R., Skirboll L., Hokfelt L., Johansson O., Lundberg J. M., Elde R. P., Terenius L. and Kimmel J. (1982b) Coexistence of somatostatin and avian pancreatic polypeptide (APP)-like immunoreactivity in some forebrain neurons. Neuroscience 7, 439-446.

Voneida T. J. and Ebbesson S. O. E. (1969) On the origin and distribution of axons in the pallial commissure in Tegu lizard (Tupinambis nigropuncatatus). Brain Behav. Evol. 2, 467-481.

Weindl A., Triepel J. and Kuchling G. (1984) Somatostatin in the brain of the turtle Testudo hermanni gmelin an immunohistochemical mapping study. Peptides 5, 91-100.

Wilson A. M. and Kriegstein A. R. (1989) Turtle cortical neurons in dissociated culture are resistant to glutamate neurotoxicity. Soc. Neurosci. Abs. 15, 763.

Young A. B., Sakurai S. Y. and Albin R. L. (1990) $\left[{ }^{3} \mathrm{H}\right] \mathrm{MK}-801$ and NMDA-sensitive $\left[{ }^{3} \mathrm{H}\right]$ glutamate binding in turtle brain. Soc. Neurosci. Abs. 16, 90. 